\title{
THE DISTRIBUTION OF THE MONTHLY 24-HOUR MAXIMUM AMOUNT OF PRECIPITATION IN ROMANIA ACCORDING TO THEIR SYNOPTIC CAUSES
}

\author{
Radu-Vlad DOBRI ${ }^{1}$, Lucian SFÎC $\breve{A}^{1}$, Pavel ICHIM ${ }^{1}$, Gabriela-Victoria HARPA ${ }^{2}$
}

DOI: $10.21163 / G T \_2017.122 .06$

\begin{abstract}
:
In the present paper we have analysed the synoptic conditions generating the maximum amount of precipitation within 24 hours in Romania. This study is based on the analysis of daily weather maps from different archived sources and also on the processing of ROCADA data set concerning the daily amount of precipitation in Romania (1961-2013). Some main weather types (WTs) - specific for the occurrence of high amount of precipitation in Romania - were established, and the daily recording of the maximum amount of precipitation for 24 hours at monthly level was assigned to one of the defined WTs. Out of the total of 312 days analysed from the synoptic point of view, a total of 133 days $(42.6 \%)$ were characterized by high atmospheric instability. The larger part of them (100 days) were determined by cold air advections associated to long-wave troughs propagating from North Atlantic towards the centre of European continent, while the rest of 33 days were generated by cut-off lows identified in the middle and upper troposphere in South-East Europe. As well, 124 days (39.7\%) were assigned to Mediterranean cyclones transiting the region of Romania and 55 days (17.7\%) were associated with Atlantic cyclones activity. The climatology of each synoptic type is presented. Also, regional and seasonal disparities are described using proper interpolation methods.
\end{abstract}

Key-words: Precipitation extremes, ROACADA database, Mediterranean cyclones, Cut-off lows Long-wave troughs.

\section{INTRODUCTION}

The studies focused on the synoptic conditions generating the highest 24-hour precipitation amounts (Apostol, 2008; Nieto et al., 2005; Porcu et al., 2007; Croitoru et al., 2016; Pfahl, 2014) indicate a variety of causes which may be linked either to the intense cyclonic activity, either to the high atmospheric instability conditions in the lower and middle troposphere.

The cyclonic activity in South-eastern Europe may be both related to the Atlantic cyclones and the Mediterranean cyclones (Șorodoc, 1962; Bordei, 2009; Garaba and Sfîcă, 2015). The genesis of the Mediterranean cyclones, and also their directions of movement have been analysed in detail within numerous studies as Alpert et al. (1990), on the basis of ECMWF data (European Centre for Medium Range Weather Forecasts) during the period from November 1982 to December 1987. These authors noticed that one of the most commonly found trajectory of cyclones is that transiting the geographical area of Romania following different paths. From November to February, the most active cyclogenetic area is

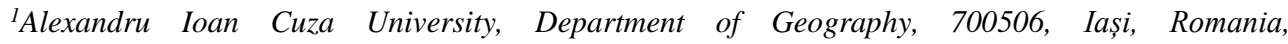
dobri.vlad@yahoo.co; sfical@yahoo.com; pavel_ichim@yahoo.com

${ }^{2}$ Babeş-Bolyai University, Department of Physic and Technical Geography, 400006, Cluj-Napoca, Romania, harpa_gabriela@yahoo.com;
} 
the Gulf of Genoa, but also the area of the Aegean Sea, or the Black Sea in a smaller percentage (Trigo et al., 2002; Trigo et al., 2006; Flocas et al., 2010). Moreover, the Mediterranean cyclones from the central-western basin, but also those from the centraleastern basin have been studied among others by Bartholy et al. (2009) on the basis of ERA-40 data (1957-2002). Their study indicated that for the latitudinal zone lying between $45^{\circ}$ and $48^{\circ}$, as far as Romania is concerned, most of the cyclones develop during spring. This type of cyclogenesis occurs mainly due to the cold air mass that meets the Alps, bypasses around the western part and in contact with the warm and moist air of the Mediterranean Sea generating cyclones which move towards the Balkan Peninsula or the Black Sea basin (Pichler et al., 1987).

Another cause for a high amount of daily precipitation is represented by the Atlantic cyclones. Even if the Icelandic Low represents one of the most important centres of action in euro-atlantic region, Icelandic lows rarely cover with their centre the region of Romania, as observed early by Topor (1970). For this reason, Atlantic cyclones play a secondary role, but not negligible, for the occurrence of a high amount of precipitation in Romania, and their influence is confined mainly to the northern and north-western regions of Romania.

The atmospheric instability which favours convective precipitation may be associated either with long-wave troughs propagating towards Eastern Europe, either with cut-off lows separated from these troughs and blocked for a couple of days in the region of Romania.

The climatology and the mechanisms of the cut-off lows systems have been studied at global level among others by McInnes et al. (1992), Holton et al., (1995), Katzfey et al. (1996), Qi et al. (1999). In the case of Europe, Nieto et al. (2005) have noted that in this region the largest number of cyclones in the entire Northern Hemisphere are formed and activated, with a high frequency during spring and summer. Their lifetime may vary from two to three days (76\%), and a very small percentage of them achieve a lifetime of over 5 days $(2.3 \%)$. They are formed mainly when the polar vortex rips apart small masses of cold air generating so-called ,polar vortex cut-off low systems” (Kentarchos et al., 1998). Numerous exchanges of energy between troposphere and stratosphere take place inside such types of atmospheric systems. Thus, it has been observed that when analysing the cyclone of the $28^{\text {th }}$ of June 1994 over the Mediterranean Sea, the warmer air at the troposphere and tropopause level is raised to the level of the stratosphere through convection, resulting in heavy precipitations at the periphery and mainly above land surface (Wirth., 1994; Wirth et al., 1999). It is important to mention that Romania is located frequently at the periphery of these systems. In order for the cyclone to develop on the ground, numerous convective cells are required, formed through cumulonimbus clouds, capable of reaching extremely high altitudes, where their peaks are radiatively cooled, leading to the mixing of air masses and to the decrease of the vertical thermal gradients (Holton et al., 1995; Price et al., 1993).

These upper level cyclones have several stages of development from tear-off to cut-off lows, both sustaining intense rainfall. In our study they are defined generaly as cut-off low systems. The main factor in the dissolution of such an upper level cyclone is convection, more precisely the consumption of cold air that maintains the atmospheric instability. The manifestation of weather is also influenced by the terrestrial area above which the cyclone is moving. For example, the most likely to suffer from harmful effects of these kinds of upper-cyclones are the strongly heated land surfaces, while the aquatic surfaces inhibit the development of convective formations (Porcu et al., 2007).

On the synoptic maps they are easily recognizable as geopotential surfaces with closely spaced isobars, filled with cold air, which enhance and sustain the deep convection in the 
troposphere below. Forecasting them and the adjacent phenomena they induce is difficult, since most of the times they manifest during an anticyclone circulation regime on the ground at continental scale (Lejenäs and Økland, 1983, Nieto et al., 2005). They represent the most common baric formations in the Mediterranean basin and the northern part of Africa (Nieto et al., 2005).

As far as the accentuated atmospheric instability is concerned, this is intensely studied at present. A special interest is given to massive precipitation over relatively short periods of time on small surfaces generating floods (Lionello et al., 2016; Pfahl, 2014; Rîmbu et al., 2016) as important phenomena resulting from the convective activity (Simeonov et al., 2009; Goodman et al., 1986; Soula et al., 1998).

\section{DATA}

The synoptic analysis was based on sea level pressure synoptic maps from Deutsche Wetterdienst and $500 \mathrm{hPa}$ geopotential height fields from Climate Forecast Systems of NOAA, archived via www.wetter3.de. The maximum amount of precipitation in 24 hours for the whole Romania was selected from ROCADA dataset (Bîrsan and Dumitrescu, 2014).

This work is based on the cartographic materials produced using GIS (TNT Mips 6.9, ArcGIS 10.3, QGis) processing software on the basis of the ROCADA database. The maximum values have been extracted from this database by grid point, at the level of Romania, within the 1961-2013 observation period, using Windows Powershell operating system through CDO operators (Schulzweida, 2017).

\section{METHODOLOGY}

In the first phase the days cumulating a high amount of precipitation for the entire study interval (1961-2015) in 24 hours were selected. This was done by selecting, from the ROCADA database, the day with the highest amount of 24-hour precipitation and the gridpoint recording this value for each month. These values were arranged from highest to lowest for each month. In order to obtain representative results, we only selected for analysis the days with values placed in the upper $40 \%$ of the monthly 24 -hour precipitation amount. This threshold of $40 \%$ is not subjective, representing, in fact, for each month, the first 26 values arranged in descending order, from all 63 months (1961-2013). This corresponds to a 24-hour precipitation amount which is the equivalent of the mean precipitation amount for the whole Romania, as resulted from ROCADA database (Table 1).

Table 1

The monthly level of $40 \%$ threshold and the mean precipitation amount for Romania.

\begin{tabular}{|c|c|c|c|c|c|c|c|c|c|c|c|c|}
\hline & $\mathrm{J}$ & $\mathrm{F}$ & $\mathrm{M}$ & $\mathrm{A}$ & $\mathrm{M}$ & $\mathrm{J}$ & $\mathrm{J}$ & $\mathrm{A}$ & $\mathrm{S}$ & $\mathrm{O}$ & $\mathrm{N}$ & $\mathrm{D}$ \\
\hline $\begin{array}{c}40 \% \\
\text { threshold }\end{array}$ & 38.8 & 37.6 & 40.1 & 45.8 & 56.3 & 66.8 & 78.4 & 65.7 & 61.1 & 54.2 & 47.7 & 44.2 \\
\hline Mean (mm) & 36.1 & 33.5 & 37.1 & 52.3 & 73.1 & 87.3 & 79.5 & 63.6 & 51.7 & 42.5 & 42.4 & 43.6 \\
\hline
\end{tabular}

In the second phase, the 312 days selected in the first step were analysed from a synoptic point of view, 6 different WTs being identified as causes for the high amount of precipitations in Romania. These WTs can be grouped in two major causes: cyclonic activity (I) and atmospheric instability (II). 
The cyclonic activity may be linked firstly to Atlantic cyclones (Ia) that generate significant precipitation in the western, northern and central parts of Romania. In this category we included the days for which a deep cyclone with Atlantic origins approaches and transits Romania with its frontal system.

Besides this, the Mediterranean cyclones having different trajectories (Şorodoc, 1962; Ion-Bordei, 1983; Garaba and Sfîcă, 2015) represent the main cause of the 24-hour precipitation amount determined by cyclonic activity in the region of Romania. The Mediterranean cyclones (Ib) analysed include the Mediterranean cyclones with trajectory I (Ib1 in our study) that affect the western parts of the country, the Mediterranean cyclones with trajectory II (Ib2), with activity especially in the southern and eastern parts (the retrogressive cyclones being also included here), and, the cyclones with trajectory IV (Ib3) that affect in particular the area above the mid-southern part of Romania. These cyclones were classified according to the criteria stated by Ion-Bordei (1983). Sea level pressure maps from Deutsche Wetterdienst archived via wetter3.de were used for the identification of the above type of cyclonic activity.

For those selected days during which the sea level pressure maps at continental scale indicated no clear cyclone activity, $500 \mathrm{hPa}$ geopotential height fields were analysed from CFS via wetter3.de in order to identify the causes of manifested atmospheric instability. Based on these the causes of atmospheric instability were grouped to two main synoptic conditions (Fig. 1). Firstly, long-wave troughs of polar vortex (IIa) propagating towards the east of Europe can displace warm tropical or polar continental air masses prior installed in the region of Romania. Secondly, deep atmospheric instability can be associated with the cut-off low systems (IIb) detached from the troughs in the region of Romania. In both cases, the mechanisms generating high amounts of precipitation are related to the atmospheric instability determined by the steep thermal gradient developed between the warm air on the ground and the colder air in middle and high troposphere.
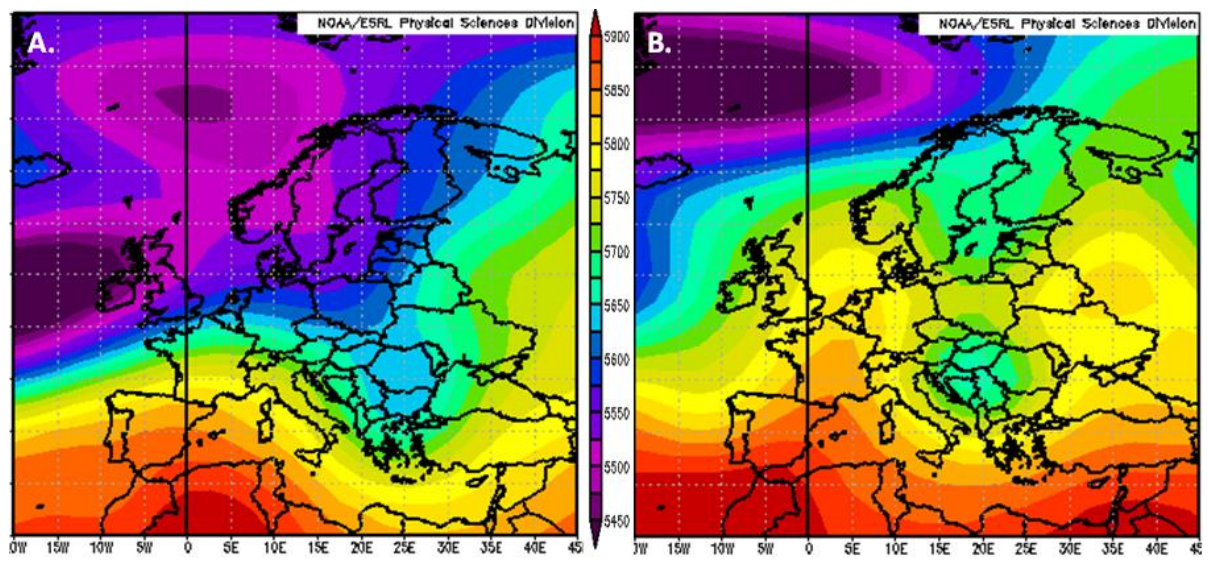

Fig. 1500 hpa geopotential height pattern for troughs (a) and cut-off lows (b) generating monthly 24hour maximum precipitation amount in Romania (a: May 12, 2009; b: July 28, 2004)

Data: NCEP/NCAR

The cartographic materials are represented by composite maps of 24-hour maximum amount of precipitation. For this, the grid point recording the monthly 24-hour amount of precipitation for the whole Romania has been extracted from ROCADA daily dataset for 
each type of synoptic condition mentioned above. To draw isohyetes, the residual kriging method was applied for all the grid points assigned to each synoptic type. Classical interpolation methods as IDW, cokriging, universal kriging, simple or ordinary kriging (Oliver, 1990) are sufficient to achieve spatial models which are good enough, particularly for the case of monthly and annual values, where the result may be largely predictable, but this aspect is not necessarily valid in the case of daily phenomena, or combinations of days with certain values or characteristics of climatic parameters (Patriche et al., 2008). Mainly for this reason the residual kriging method has been used to draw the composite maps in our study, as it does not depend on a certain function of the software, the residual values being strictly dependent on the local factors in the field. This is the reason why this methohd increase the accuracy of the product in particular in the mountainous regions which are known as difficult to be mapped, especially when it comes to climatic parameters (Prudhomme, 1999).

\section{RESULTS AND DISCUSSIONS}

In Romania, the regime of precipitation generally displays a continental pattern, in particular during the warm semester of the year, having its maximum in July, with a highlighted role of convective precipitation due to periods of enhanced atmospheric instability (Apostol, 2008). The differences between the cold semester and the warm semester consist in the frequency of the dynamic factors, but also of the areas they affect. Therefore, according to the histogram of the two semesters (Fig. 2), during the cold semester the Atlantic cyclones prevail as a cause for the 24-hour maximum amount of precipitation in Romania, followed by Mediterranean cyclones with trajectories II and IV (Ib2 and Ib3 in Fig. 2). During the warm semester the Mediterranean cyclones with trajectory II ( $\mathrm{Ib} 2$ ) prevail in particular at the beginning and at the end of the semester, while the situations of atmospheric instability (IIa and IIb in Fig. 2) are dominant especially during midsummer.

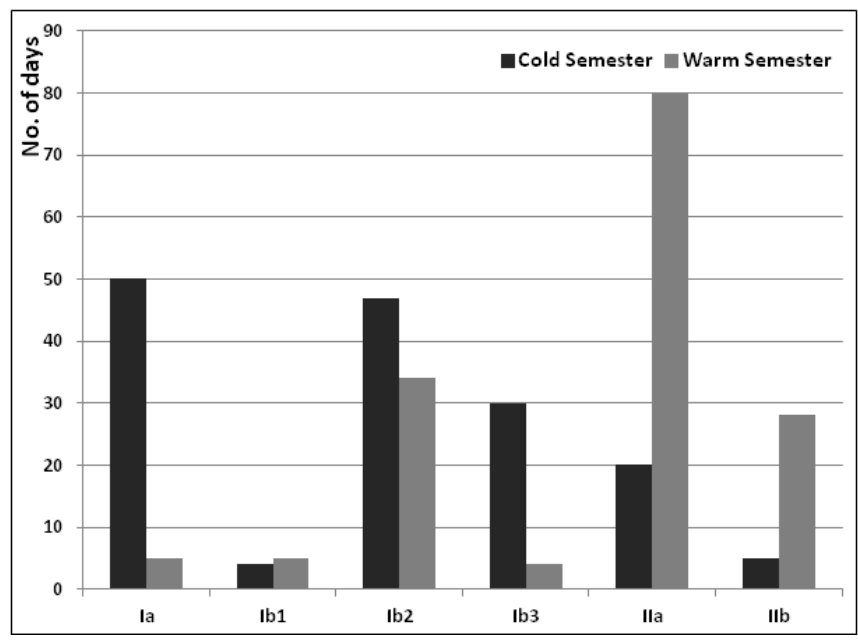

Fig. 2 Synoptic causes of 24 hour maximum amount of precipitation in Romania for warm (April to September) and cold (October to March) semester 
Atlantic cyclones (Ia) gather 55 days (Table 2), most of them in December (13 cases), but also in February and March (11 and 10 cases respectively). The areas inside the Carpathian Arch frequently record the monthly 24-hour maximum amount of precipitations for Romania from this type of cyclonic activity (Fig. 3A). In the same time, the exterior of the Carpathians region receives just poor amounts of precipitation from this pluviogenetic source due to the long way to travel above an extremely diverse terrain (Apostol, 2008). The increased frequency of Atlantic cyclones as genetic cause for the monthly 24-hour maximum amount of precipitation in Romania takes place during autumn at the same time with the extension towards the south of the Icelandic cyclone'trough, due to the decrease of the baric field in the South-Eastern Europe, which determines the increase of situations of infiltration of continental cold air from the north-west to the Balkan Peninsula. As a result of this fact, the Atlantic cyclone activity is again growing, especially in the second part of the cold season (February-March).

Table 2

Synoptic causes (no of cases) for the 24 hour maximum amount of precipitation in Romania.

\begin{tabular}{|c|c|c|c|c|c|c|}
\hline & $\begin{array}{c}\text { Atlantic } \\
\text { Cyclones: } \\
\text { Ia }\end{array}$ & $\begin{array}{c}\text { Med. I: } \\
\text { Ib1 }\end{array}$ & $\begin{array}{c}\text { Med. II: Ib2 } \\
\text { (from which } \\
\text { retrogressive } \\
\text { cyclones) }\end{array}$ & $\begin{array}{c}\text { Med. IV: } \\
\text { Ib3 }\end{array}$ & $\begin{array}{c}\text { Troughs: } \\
\text { IIa }\end{array}$ & $\begin{array}{c}\text { Cut-off } \\
\text { lows: IIb }\end{array}$ \\
\hline Jan & 8 & 0 & $11(2)$ & 7 & 0 & 0 \\
\hline Feb & 11 & 0 & $9(2)$ & 6 & 0 & 0 \\
\hline Mar & 10 & 1 & $9(2)$ & 4 & 1 & 1 \\
\hline Apr & 0 & 1 & $15(7)$ & 2 & 5 & 3 \\
\hline May & 4 & 2 & $4(3)$ & 0 & 14 & 2 \\
\hline Jun & 0 & 2 & $7(2)$ & 1 & 16 & 0 \\
\hline Jul & 0 & 0 & $4(0)$ & 0 & 17 & 5 \\
\hline Aug & 0 & 0 & $1(0)$ & 1 & 19 & 5 \\
\hline Sep & 1 & 0 & $3(0)$ & 0 & 9 & 13 \\
\hline Oct & 3 & 1 & $3(1)$ & 4 & 13 & 2 \\
\hline Nov & 5 & 1 & $10(3)$ & 4 & 5 & 1 \\
\hline Dec & 13 & 1 & $5(0)$ & 5 & 1 & 1 \\
\hline
\end{tabular}

The situation is quite the opposite during the warm semester, as this genetic cause has the lowest frequency. Out of the total of 156 days analysed in the warm semester, only 5 were characterized by this genetic cause (4 in May and only one day in September). The highest values of monthly 24-hour precipitation amount caused by Atlantic cyclones were registered in Vlădeasa Massif at Stâna de Vale region, where 19 of the 312 days have maximum values in these conditions.

The map of precipitation imprint of the Atlantic cyclones in Romania (Fig. 3A) has been determined by extracting the maximum 24-hour quantities of the 55 days. In this case the maximum amount of precipitation is reached in the northern part of the country and in the Apuseni Mountains, with an important contribution of the orographic effect on the western flank of Carpathian Mountains (Maramureș, Stâna de Vale). Also, a high amount of precipitation is specific to the central part of the Romanian Plain due to convergence lines which can form in this region due to the modification of the westerly flow under the effect of the Carpathian Mountains (Bordei-Ion, 1988). Also, the northern part of Moldova 
receives equally important amounts of precipitation under the same synoptic conditions probably due to its physico-geographic characteristics (Apostol and Sfîcă, 2011).

As far as the Mediterranean cyclones (Ib) are concerned, even though they are particularly representative for the cold semester, their activity in the warm semester is also quite important.

In what concerns the cyclones with trajectory I (Ib1 in Fig. 1), crossing with their center the Pannonian region and being felt in particular in the north-western half of Romania, they present only 11 cases, mostly concentrated from March to June (6 cases).

The Mediterranean cyclones with trajectory II (Ib2) are the most frequent with 81 cases. The retrogressive cyclones ( 22 cases) have been also included to the cyclones with trajectory II (12 in the warm semester and 10 in the cold semester) with April gathering the majority of cases (7). They have an initial movement on a normal trajectory II, but when they arrive above the Black Sea they switch to a retrogressive movement and come again over the territory of Romania generating significant precipitation especially in the eastern part of Romania.

Cyclones with trajectory IV (Ib3), affecting in particular the southern half of Romania, induce the highest values of precipitation in the central-southern part of the Romanian Plain and on the southern slopes of the Carpathians and Subcarpathians, being identified in 34 cases with the highest frequency from October to March.

The most intense activity of these cyclones takes place in the cold semester of the year even if the activity of the Mediterranean cyclones is lower in October and December when the anticyclonic regimes are prevalent (Stăncescu, 1983). In the months of December, January, February, and March the Mediterranean cyclones are formed most of the times in the central-eastern part of the Mediterranean Sea basin, those being also the months with the most intense cyclone activity on the Romanian territory (Alpert et al., 1990), in particular on trajectory II and IV. It has also been noted that during November and March, the Gulf of Genoa is by far the most active area from the point of view of Mediterranean cyclogenesis (Trigo et al., 2002)

The map showing the distribution of 24-hour maximum amount of precipitation caused by the Mediterranean cyclones with trajectory I (Fig. 3B) indicates the entire western area, the south-western, north-western, north-eastern, and the central areas of the country as being the most influenced by these cyclones.

According to the similar map for the Mediterranean cyclones with trajectory II (Fig. 3C) we may notice that the precipitation produced by them are most of the times quantitatively significant (a maximum value of $124 \mathrm{~mm}$, registered on the $10^{\text {th }}$ of May 1973). The most affected area by these cyclones are the Meridional Carpathians, and the surrounding areas the orographic lifting on the southern flanks of this mountains playing an important role for the occurence of this wet region. The eastern half of Romania, more precisely Moldova region and the eastern of the Romanian Plain presents as well high values of precipitation during these conditions (70 and $100 \mathrm{~mm}$ ), especially due to the contribution of retrogressive cyclones included in this category.

The cyclones with trajectory IV (Fig. 3D) affect especially the southern half of Romania due to their southerly path over the Balcan Peninsula.

Beside the cyclonic activity, the atmospheric instability represents the main contributor for high amount of precipitation within 24 hours especially during summer. 


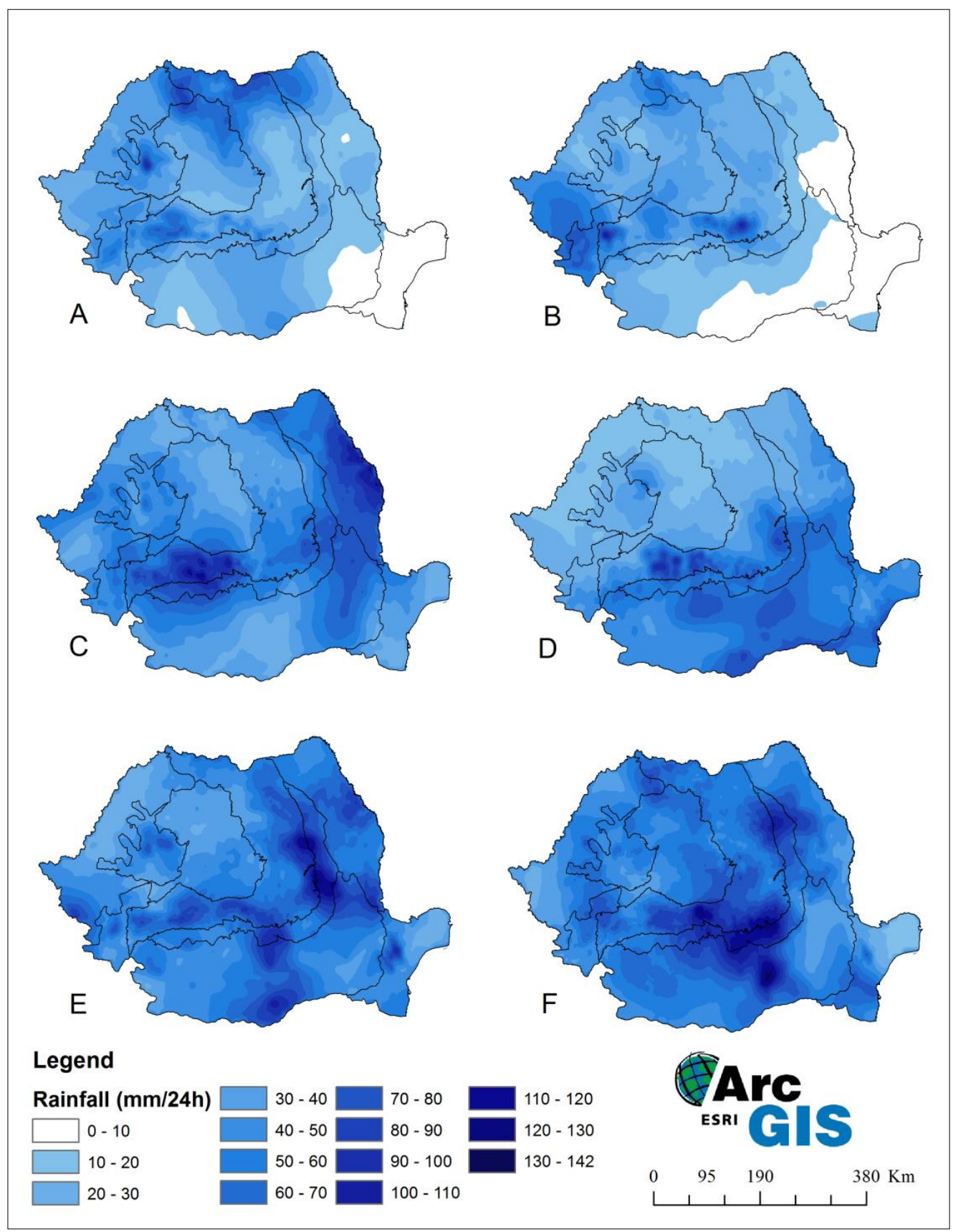

Figure 3 Composite maps of 24-hour maximum precipitation amount distribution in Romania generated by Atlantic cyclones (A), Mediterranean cyclones following Ib1(B), Ib2(C) or Ib3 (D) trajectories, troughs $(\mathrm{E})$ and cut-off lows $(\mathrm{F})$ 
The most important cause of atmospheric instability (II) in term of frequency is associated with long-wave troughs propagating towards the east of the continent (IIa) from North Atlantic. The regions which receive the highest amount of precipitation during these conditions are the areas located at the contact of Subcarpathians and Carpathians (Fig. $\mathbf{3 E}$ ), this being the area where most of the times the interaction between the pre-existent cold and warm masses takes place. In these regions the atmospheric instability is also enhanced by orographic lifting effect which is capable of increasing the rainfall amount.

From 100 days presenting these conditions April and September present the lowest number of cases, with 5 and 9 days respectively, while the intensive activity begins with the month of May, having 14 cases, and is continued with June, July, and August with 16, 17, and 19 cases respectively (Table 2).

The cut-off low cyclones from altitude (IIb) gather 33 cases, most of them in the months of the beginning and the end of the warm semester. So, April and May present 3 and 2 cases respectively, while the month of September has allocated 13 cases (Table 2). This higher frequency is generated by the dynamics of the air masses of this period of the year, characterized by rising warm air and descending cold air in lower latitudes. In the summer months their activity is comparable to other synoptic situations, presenting a number of 10 cases, 5 in July and 5 in August. The convective activity generated by the cutoff low cyclones of altitude in the cold semester is less importantant (only 5 cases from which 2 are recorded in October).

The composite map of monthly 24-hour amount of precipitation for this type of atmospheric manifestation of instability (Fig. 3F) has been made by extracting the maximum values of the 33 days. At a first sight it is noted that the areas with the highest values are arranged somewhat chaotically for the whole country, with no specific areas contributing to the formation of the convective structures. However, it has been observed that some of them have been formed on the slopes with southern exposition, strongly heated, or in regions of low altitude, as the Subcarpathian hills where the temperature of the active surface is much higher prior to the advection of cold air mass. As expected, the area with the lowest values is the Dobrogea Plateau, but especially the Danube Delta, with extended area of water that inhibits the convective development.

An example in this case is the cyclone from September 19-22, 2005, a cyclone in altitude that did not completely reached the cut-off phase led to the occurence of the highest value of the entire data set (142 $\mathrm{mm}$ in the region of Bucharest), having affected the whole central-southern area of the Romanian Plain.

\section{CONCLUSIONS}

The genetic causes of the monthly 24-hour maximum amount of precipitation are highly different between the cold and warm semester in the region of Romania. Also, Atlantic and Mediterranean cyclones are more common in generating high amount of precipitation in 24 hours during cold semester. Opposingly, during the warm semester the atmospheric instability is imposed either by the propagation of troughs from west to east inside the continent, either by cut-off lows systems located in the region of Romania, both cases being fuelled by a strong instability throughout the entire troposphere. Actually, the most important contribution of this study consists in underlying the importance of atmospheric instability during the warm semester. Also, some regional disparities are identified, Atlantic cyclones or Mediterranean cyclones following trajectory I generating high amounts of precipitation in the central and western Romania, while Mediterranean 
cyclones following trajectory II generate higher monthly 24-hour amount of precipitation in Moldova. Also, Mediterranean cyclones following trajectory IV are more important for the high amount of precipitation in the southern part of the country. Troughs and cut-off lows generally induce a high amount of precipitation in Romania, regardless of the region, but certain prevalence can be spotted for regions situated outside of the Carpathian region, especially for those where the orographic pluviogenetic effect is felt (Subcarpathian region and the eastern flanks of Carpathian Mountains).

\section{ACKNOWLEDGMENT}

This research was developed under the framework of the research grant Extreme weather events related to air temperature and precipitation in Romania (project code: PN-IIRU-TE-2014-4-0736), funded by the Executive Unit for Financing Higher Education, Research, Development, and Innovation (UEFISCDI) in Romania.

\section{R E F E R E N C E S}

Alpert, P., Neeman, B. U., \& Shay-El, Y. (1990) Intermonthly variability of cyclone tracks in the Mediterranean. Journal of Climate, 3(12), 1474-1478.

Apostol, L. (2008) The Mediterranean cyclones-the role in ensuring water resources and their potential of climatic risk, in the east of Romania. Present Environment and Sustainable Development, 2, 143-163.

Apostol L., Sfîcă L. (2011) Topoclimatic wind peculiarities induced by the Siret corridor morphology. Prace i Studia Geograficzne, T. 47, ss. 483-491, Warsaw, Poland.

Bartholy, J., Pongrácz, R., \& Pattantyús-Ábrahám, M. (2009) Analyzing the genesis, intensity, and tracks of western Mediterranean cyclones. Theoretical and Applied Climatology, 96(1-2), 133144.

Bîrsan M.-V., Dumitrescu A. (2014) ROCADA: Romanian daily gridded climatic dataset (19612013) V1.0. Administrația Națională de Meteorologie, București, România, doi:10.1594/PANGAEA.833627.

Ion-Bordei E. (1983) The role of alpino-carpathian mountains chain for the evolution of mediterranean cyclones (in romanian). Editura Academiei, Bucureşti.

Croitoru, A. E., Piticar, A., \& Burada, D. C. (2016) Changes in precipitation extremes in Romania. Quaternary International, 415, 325-335.

Flocas, H. A., Simmonds, I., Kouroutzoglou, J., Keay, K., Hatzaki, M., Bricolas, V., \& Asimakopoulos, D. (2010) On cyclonic tracks over the eastern Mediterranean. Journal of Climate, 23(19), 5243-5257.

Garabă, L., \& Sfîcă, L. (2015) Climatic features of the romanian territory generated by the action of mediterranean cyclones. Lucrările Seminarului Geografic" Dimitrie Cantemir", 39(1), 11-24.

Goodman, S. J., \& MacGorman, D. R. (1986) Cloud-to-ground lightning activity in mesoscale convective complexes. Monthly Weather Review, 114(12), 2320-2328.

Holton, J. R., Haynes, P. H., McIntyre, M. E., Douglass, A. R., Rood, R. B., \& Pfister, L. (1995) Stratosphere-troposphere exchange. Reviews of Geophysics, 33(4), 403-439.

Katzfey, J. J., \& Mcinnes, K. L. (1996) GCM simulations of eastern Australian cutoff lows. Journal of Climate, 9(10), 2337-2355.

Kentarchos, A. S., and T. D. Davies (1998) A climatology of cut-off lows at $200 \mathrm{hPa}$ in the Northern Hemisphere, 1990-1994. International Journal of Climatology, 18, 379-390.

Lejenäs, H., Okland, H.(1983) Characteristics of northern hemisphere blocking as determined from a long time series of observational data. Tellus, 35A: 350-362.

Lionello, P., Trigo, I. F., Gil, V., Liberato, M. L., Nissen, K. M., Pinto, J. G., Ulbrich, S., \& Ulbrich, W. (2016) Objective climatology of cyclones in the Mediterranean region: a consensus view among methods with different system identification and tracking criteria. Tellus A, 68 . 
McInnes, K. L., \& Hess, G. D. (1992) Modifications to the Australian region limited area model and their impact on an east coast low event. Australian Meteorological Magazine, 40(1).

Nieto, R., Gimeno, L., de La Torre, L., Ribera, P., Gallego, D., García-Herrera, R., García, J.A., Nuñez, M., Redaño, A., \& Lorente, J. (2005) Climatological features of cutoff low systems in the Northern Hemisphere. Journal of Climate, 18(16), 3085-3103.

Oliver, M. A., \& Webster, R. (1990). Kriging: a method of interpolation for geographical information systems. International Journal of Geographical Information System, 4(3), 313-332.

Patriche, C., Sfîcă, L., \& Roşca, B. (2008). About the problem of digital precipitations mapping using (geo) statistical methods in GIS. Geographia Technica, 1, 82-91.

Pfahl, S. (2014) Characterising the relationship between weather extremes in Europe and synoptic circulation features. Natural Hazards and Earth System Sciences, 14(6), 1461.

Pichler, H., \& Steinacker, R. (1987) On the synoptics and dynamics of orographically induced cyclones in the Mediterranean. Meteorology and Atmospheric Physics, 36(1), 108-117.

Porcu F., Carassi A., Medaglia C. M., Prodi F., Mugnai A. (2007) A study on cut-off low vertical structure and precipitation în the Mediterranean region. Meteorology and Atmospheric Physics, Nr. 96, 121-140.

Price, J. D., \& Vaughan, G. (1993) The potential for stratosphere-troposphere exchange in cut-off-low systems. Quarterly Journal of the Royal Meteorological Society, 119(510), 343-365.

Prudhomme, C., \& Reed, D. W. (1999) Mapping extreme rainfall in a mountainous region using geostatistical techniques: a case study in Scotland. International Journal of Climatology, 19(12), 1337-1356.

Qi, L., L. M. Leslie, and S. X. Zhao (1999) Cut-off low pressure systems over southern Australia: Climatology and case study. International Journal of Climatology, 19, 1633-1649.

Rîmbu, N., Ștefan, S., Busuioc, A., \& Georgescu, F. (2016) Links between blocking circulation and precipitation extremes over Romania in summer. International Journal of Climatology, 36(1), 369-376.

Schulzweida, U. (2017) CDO user guide. Climate Data Operators, version 1.8.1. [Online] Available from: https://code.mpimet.mpg.de/projects/cdo/embedded/cdo.pdf [Accessed May-July 2017].

Simeonov, P., Bocheva, L., \& Marinova, T. (2009) Severe convective storms phenomena occurrence during the warm half of the year in Bulgaria (1961-2006). Atmospheric Research, 93(1), 498505.

Şorodoc C., (1962) Formarea și evoluția ciclonilor mediteraneeni și influența lor asupra timpului în R. P. R., Culegere de lucrări a Institutului Meteorologic pe anul 1960, București.

Soula, S., Sauvageot, H., Molinie, G., Mesnard, F., \& Chauzy, S. (1998) The CG lightning activity of a storm causing a flash-flood. Geophysical Research Letters, 25(8), 1181-1184.

Stăncescu I., (1983) Carpathian mountains, modifiers factors of climate. Editura Știinţifică și Enciclopedică, București.

Trigo, I. F., Bigg, G. R., \& Davies, T. D. (2002) Climatology of cyclogenesis mechanisms in the Mediterranean. Monthly Weather Review, 130(3), 549-569.

Trigo, I. F. (2006) Climatology and interannual variability of storm-tracks in the Euro-Atlantic sector: a comparison between ERA-40 and NCEP/NCAR reanalyses. Climate Dynamics, 26(2-3), 127143.

Topor, N., (1970) The causes of some exceptional rainfalls in Romania (in romanian), Hidrotehnica, 15 (11).

Wirth, V. (1995) Diabatic heating in an axisymmetric cut-off cyclone and related stratosphere-troposphere exchange. Quarterly Journal of the Royal Meteorological Society, 121(521), 127-147.

Wirth, V., \& Egger, J. (1999) Diagnosing extratropical synoptic-scale stratosphere-troposphere exchange: A case study. Quarterly Journal of the Royal Meteorological Society, 125(554), 635655.

www1.wetter3.de for the archived GFS analyse [Accessed May 2017]. 